Journal of Electronic

Voltage and

Application

\title{
Economical Electricity Home System using Solar
}

\author{
Aisha Ajeerah Azahar ${ }^{1}$, Nor Akmal Mohd Jamail ${ }^{1, *}$, Amal Hayati Mat Isa ${ }^{1}$, \\ Fatin Nazirah Md Sani ${ }^{1}$, Danial Hakim Mohd Razali ${ }^{1}$, Muhammad Badrul \\ Munir Busu', Qamarul Ezani Kamarudin²
}

\author{
${ }^{1}$ Faculty of Electrical and Electronic Engineering, \\ Universiti Tun Hussein Onn Malaysia, Parit Raja, Batu Pahat, 86400, MALAYSIA \\ ${ }^{2}$ Faculty of Mechanical and Manufacturing Engineering, \\ Universiti Tun Hussein Onn Malaysia, Parit Raja, Batu Pahat, 86400, MALAYSIA \\ *Corresponding Author
}

DOI: https://doi.org/10.30880/jeva.2021.02.02.011

Received 05 July 2021; Accepted 26 July 2021; Available online 30 December 2021

\begin{abstract}
Economical home system can be defined as one realization of home that have a cost-effective ideal by using specific set of technologies combined with the renewable energy as a power supply. This system has a highly advance for lighting, temperature control, socket and own power supply by using solar panel. This system is developed in this project and focused on B40 community that represents the bottom $40 \%$ of income earners and also this project becomes suitable for this community for getting an energy efficiency system. Due to the COVID19, B40 households were reported to have lost their jobs causing financial hardship and had to face the issue of high electricity bills which are very burdensome for them at all in order to pay the cost electricity for monthly. The aim of the article is to design and simulate the solar power system including battery storage in suitable software for a residential house especially in B40 community home and also to analyze the potential of battery storage in order to store the energy from solar panel. Therefore, the economical electricity home system using solar energy for B40 community is proposed in this project for producing an energy efficient system at home. In addition, an electrical floor plan and floor plan of B40 community home is designed in the SketchUp software that using basic electrical equipment such as lighting, ceiling fan and socket. The system is developed by using the MATLAB software in order to produce the result of energy efficiency by using the renewable energy which is solar system and also battery storage. According to the data produced from the calculation of old bills and new bills, the energy consumptions are calculated and also be compared before and after using the renewable energy which is using solar system. The data obtained through calculation of maximum demand in new bill is used in the simulation of solar system in MATLAB software. The results obtained show that after using an energy-efficient load, the monthly new bill is around RM 27.79 which is around RM 10.75 less than the monthly old bill before using an energy-efficient load. It can be concluded that the use of renewable energy in B40 community home can save the energy and also money.
\end{abstract}

Keywords: Economical electricity home, solar system, battery storage, MATLAB

\section{Introduction}

The development of new technologies in Malaysia keep increasing and their unification with older traditional building technologies, economical home system is finally becoming a real possibility. Although this home system is not a new term for the scientific community but it is still far from the vision and audition of people especially rural people. Economical home system can be defined as one realization of home that have a cost-effective ideal by using specific set 
of technologies combined with the renewable energy as a power supply [1]. This system has a highly advance for lighting, temperature control, socket and own power supply by using solar panel.

This project focused on B40 community that represents the bottom $40 \%$ of income earners [2]. These people can be found in rural areas and also in cities with the lowest income group with RM 4,849 and below [3].

As solar system will be used as renewable energy in this project that benefit for B40 community in order to save an energy consumption and helping in managing community expenses. So that, this project will be focused on solar energy system for building an economical electricity system. In addition, a switch to renewable energy can reduce global warming emissions and air pollution in Malaysia [4-5]. Solar energy become suitable for B40 community due to this system provide a cheaper, cleaner alternative and also Malaysia location in the equatorial zone for getting the abundant sunlight [6]. The use of battery storage will be introduced in this project for storing the energy for later use especially at night. By installing energy storage technologies like solar batteries can more easily manage the flow of electricity from renewable resources which is solar energy [7].

The demand for electrical energy become increasing in this country especially during COVID-19 where the people be advised to work from home and also be asked to stay at home in order to keep this pandemic decrease. Besides that, B40 households were reported to have lost their jobs due to the Covid-19 pandemic, causing financial hardship [8-9]. Due to this problem, B40 people had to face this issue of high electricity bills which are very burdensome for them at all in order to pay the cost electricity for monthly. Therefore, the economical electricity home system using solar energy for B40 community will proposed in this project for producing an energy efficient system at B40 home. The solar energy system including battery storage for B40 community home is designed and simulate in MATLAB software and the potential of battery storage to store the energy from solar panel is analyze in this project.

\section{Methodology}

The project methodology focusses on the development of the solar system and battery storage system in MATLAB software. The first subsection presents on the overall work flow of in this project that described in flowchart, the block diagram of the main system which is solar and battery storage system, followed by the B40 community home layout development.

\subsection{Project Flow Design}

Figure 2.1 below shows the flowchart of the work process on developing this project especially an economical electricity home system using solar energy that can supply electricity at B40 community home. It is beginning with collecting information and theories from website or research papers related to this project. After have some discussion with teammates, all agreed to continue the project by sketching the smart home floor plan using SketchUp software which are the floor plan layout and also electrical floor plan. Next, step is constructing the solar panel circuit in the MATLAB software based on the power demand that has been calculated manually. Then, the performance of the simulation is tested for observing the condition of solar panel either it is fulfilling the requirement or not. Whenever the error during the simulation, the parameters and conditions of the solar panel design are revised and checked thoroughly across the settings of the software. If the simulation is executed successfully, the results will be collected for further analysis before end the project with constructing the final report.

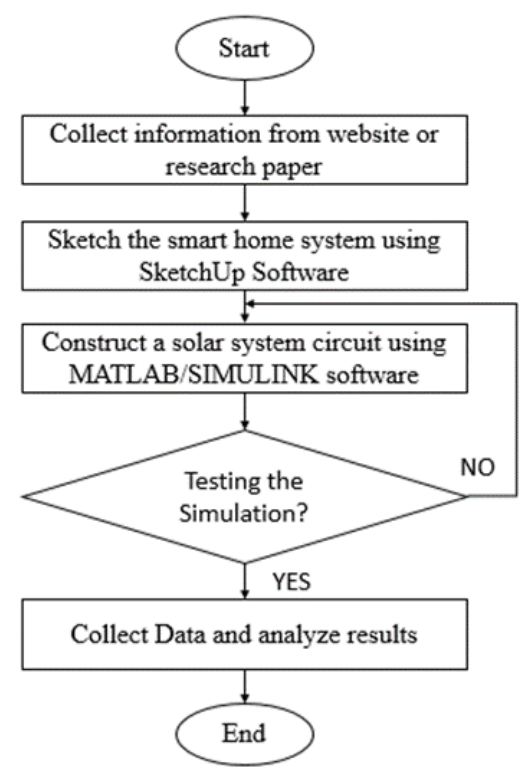

Figure 2.1 - Overall flowchart of the project 


\subsection{Block Diagram of the System}

Figure 2.2 show the block diagram of developed system which are solar and battery storage system. The solar panel was designed to absorb available solar energy into electricity and it has four series connected modules which is 30 volts with 250 Watt for each module. Therefore, the systems need 120 volts with 1000 -Watt AC loads to be simulate using MATLAB software. The energy stored in the solar panel will be step up while the current will be step down before it is transferred to the output AC loads. In addition, the bidirectional DC-DC converters are implemented in this system as continuous power flow is necessary to charge the battery as well as maintaining the voltage source about 240 volts once the voltage drops [10]. The bidirectional converter will undergo boost mode, increasing the input voltage from the battery to maintain the voltage. Simultaneously, the battery will begin to discharge as the voltage at the DC connection decreases. Then, an inverter is also used in this solar system to convert the DC input to the AC output of voltage and current. The inverter utilized is a single-phase full-bridge inverter as the output power from this inverter will produce four times that of a half bridge inverter that will be transferred into the AC loads.

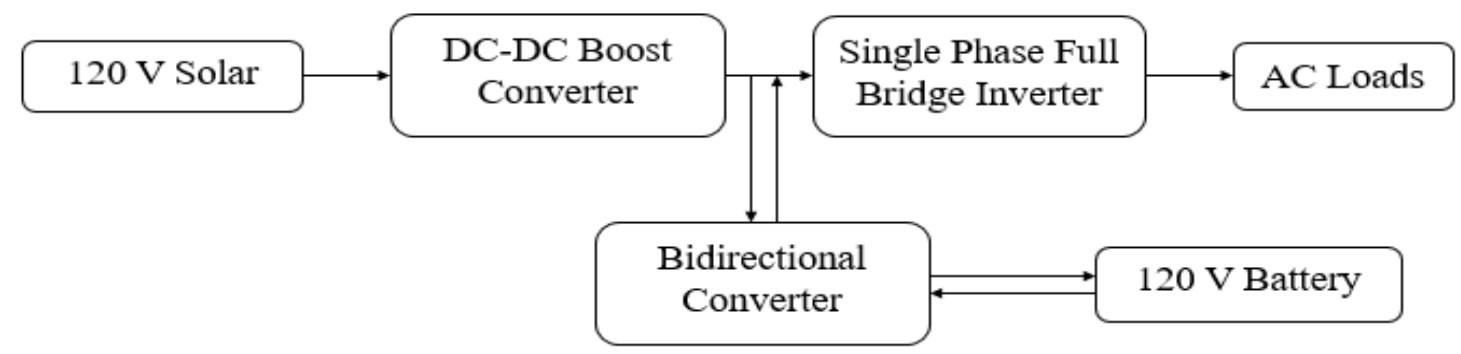

Figure 2.2 - Block Diagram of developed system

\subsection{B40 Community Home Layout Development}

This section presents a design of the home floor plan and its electrical layout for the B40 group using SketchUp software. This layout is used to calculate the maximum demand needed as it will be the input of the solar system simulation. Figure 2.3 shows the top view of the 3D floor plan layout. It is consisting of basic appliances which is enough to accomplish the B40 household functions such as washing laundry, refrigerator, kitchen stove, rice cooker and freezer.

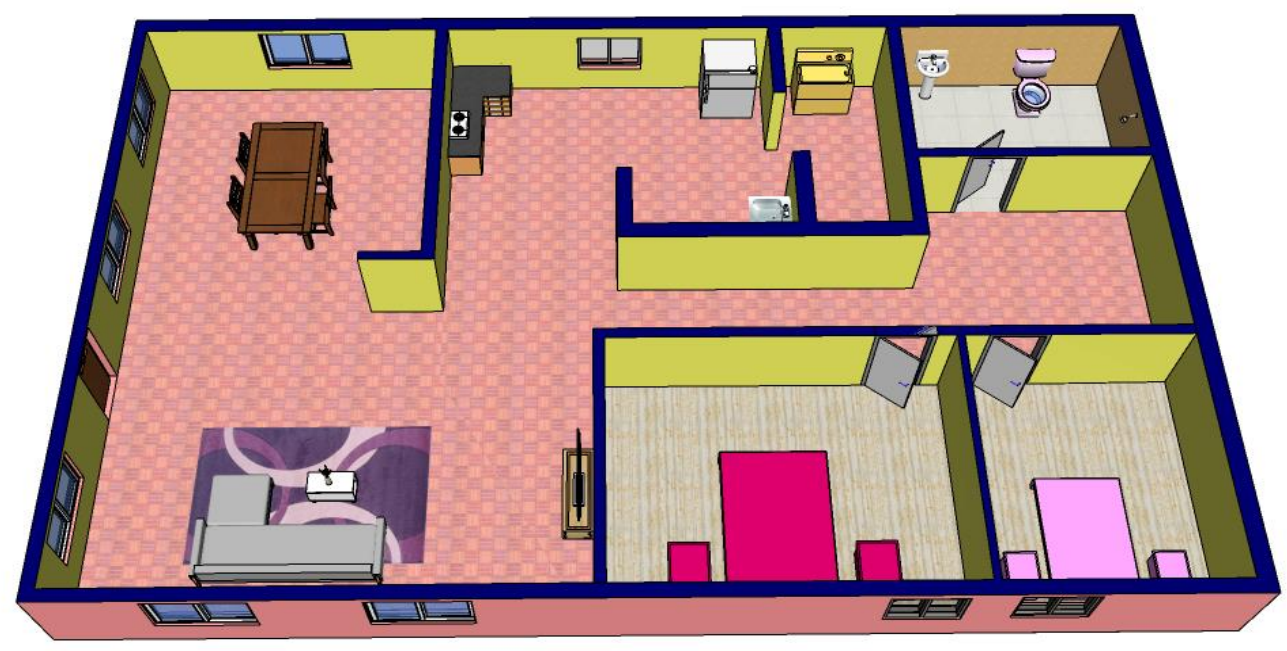

Figure 2.3 - Top view of 3D floor plan layout

Moreover, the design of electrical floor plan layout in 2D for the B40 household also designed using SketchUp software as shown in figure below. The dimensions that has been discussed for this layout is $14840 \mathrm{~mm}$ length $\times 9500$ $\mathrm{mm}$ width. This project also using a basic electrical appliance which are ceiling fan, lighting and also 13 A Switch Socket Outlet (SSO) as shown in Figure 2.4. The details of the electrical components used for this smart home explained as shown in Table 2.5 . 




Figure 2.4 - Electrical floor plan layout

Table 2.5 - Electrical component

\begin{tabular}{llll}
\hline No. & $\begin{array}{r}\text { Electrical } \\
\text { component }\end{array}$ & Symbol & Quantity \\
\hline 1 & Ceiling Fan & 1 \\
\hline 3 & Lighting & 13 A SSO & 6 \\
\hline
\end{tabular}

\section{Result and Discussion}

This section is divided into two parts which are the result obtained through electricity bill comparison before and after using this system and the result obtained through simulation of solar and battery storage system.

\subsection{Electricity Bill Comparison}

This section will compare the electricity bill between the old and new bills after using energy-efficient load such as ceiling fan, lighting and socket in B40 house in order to analyze which one is better and have the lowest monthly bill as shown in Table 3.1 until Table 3.6. 90 percent from 30 respondents of B40 community agreed that an energy consumption is around $150-200 \mathrm{kWh}$. The energy consumption or electricity bill is calculated by using the various formula of total maximum demand and total connection load. For ceiling fan, a 98 Watt of load rating is used due to the lesser electricity consumed and it is suitable for the dimensions of the B40 household living room. Usually, about 15100 watts of energy used for each ceiling fan after considering the dimensions of the room, size of fan, airflow, its length and how many blades, their materials and more. A 40 watts of lighting used is capable of drawing about $0.36 \mathrm{~A}$, where its wattage is divided by 110 volts. The $0.36 \mathrm{~A}$ for lighting system is efficient for the B40 household as it consume lower current which leads to produce lower maximum demand. Besides, around 230 volts is used for the $13 \mathrm{~A}$ $\mathrm{SSO}$ as it is the highest rated fuse used for a plug including the multiway adapters. When 230 volts multiply with the 13 A, there will be only up to 2990 watts of devices can be connected into it. 
Table 3.1: Calculation of old bill

\begin{tabular}{|c|c|c|c|c|c|c|}
\hline No. & Description & Quantity & $\begin{array}{l}\text { Load } \\
\text { rating } \\
\text { (Watt) }\end{array}$ & $\begin{array}{c}\text { Total } \\
\text { connected } \\
\text { load } \\
\text { (Watt) }\end{array}$ & $\begin{array}{c}\text { Demand } \\
\text { factor }\end{array}$ & $\begin{array}{c}\text { Maximum } \\
\text { demand } \\
\text { (Watt) }\end{array}$ \\
\hline 1 & Ceiling fan & 1 & 98 & 98 & 0.8 & 78.4 \\
\hline 2 & Lighting & 8 & 40 & 320 & 0.8 & 256 \\
\hline 3 & 13A SSO & 6 & 250 & 1500 & 0.5 & 750 \\
\hline & & & \multicolumn{3}{|c|}{ Total maximum demand (Watt) } & 1084.4 \\
\hline & & & \multicolumn{3}{|c|}{ Coincident factor (ESAH) } & 0.9 \\
\hline & & & \multicolumn{3}{|c|}{ Maximum demand (Watt) } & 975.96 \\
\hline
\end{tabular}

Table 3.2 - Energy consumption bill in one month (old bill)

\begin{tabular}{ccccc}
\hline $\begin{array}{c}\text { Types of } \\
\text { load }\end{array}$ & $\begin{array}{c}\text { Total } \\
\text { power } \\
(\mathbf{W})\end{array}$ & $\begin{array}{c}\text { Maximum } \\
\text { demand } \\
(\mathbf{W})\end{array}$ & $\begin{array}{c}\text { Hours per } \\
\text { month }(\mathbf{h r s})\end{array}$ & $\begin{array}{c}\text { Energy } \\
\text { consumption } \\
(\mathbf{k W h})\end{array}$ \\
\hline Ceiling fan & 98 & 78.4 & $(12 \times 30)=360$ & 28.224 \\
\hline Lighting & 320 & 256 & $(6 \times 30)=180$ & 46.08 \\
\hline 13A SSO & 1500 & 750 & $(4 \times 30)=120$ & 90.000 \\
\hline & Total kWh & & 164.304 \\
\hline $\begin{array}{c}\text { Tariff } \\
(\mathbf{k W h})\end{array}$ & Rate & Power used & Amount \\
$(\mathbf{k W h})$ & \\
\hline $\begin{array}{c}\text { For the first } 200 \mathrm{kWh} \\
(1-200 \mathrm{kWh}) \text { per } \\
\text { month }\end{array}$ & RM0.218 & 164.304 & 35.82 \\
\hline & Total & & 164.304 & 35.82 \\
\hline
\end{tabular}

Table 3.3 - Calculation of new bill

\begin{tabular}{ccccccc}
\hline No. Description & Quantity & $\begin{array}{c}\text { Load } \\
\text { rating } \\
\text { (Watt) }\end{array}$ & $\begin{array}{c}\text { Total } \\
\text { connected } \\
\text { load (Watt) }\end{array}$ & $\begin{array}{c}\text { Demand } \\
\text { factor }\end{array}$ & $\begin{array}{c}\text { Maximum } \\
\text { demand } \\
\text { (Watt) }\end{array}$ \\
\hline 1 & Ceiling fan & 1 & 51 & 51 & 0.8 & 40.8 \\
\hline 2 & Lighting & 8 & 12 & 96 & 0.8 & 76.8 \\
\hline 3 & 13A SSO & 6 & & 250 & 1500 & 0.5 \\
\hline
\end{tabular}

3.4 - Energy consumption bill in one month (new bill)

\begin{tabular}{|c|c|c|c|c|}
\hline $\begin{array}{l}\text { Types of } \\
\text { load }\end{array}$ & $\begin{array}{c}\text { Total } \\
\text { power } \\
(W) \\
\end{array}$ & $\begin{array}{c}\text { Maximum } \\
\text { demand } \\
(W) \\
\end{array}$ & $\begin{array}{l}\text { Hours per } \\
\text { month (hrs) }\end{array}$ & $\begin{array}{c}\text { Energy } \\
\text { consumption } \\
(\mathbf{k W h}) \\
\end{array}$ \\
\hline Ceiling fan & 51 & 40.8 & $(12 \times 30)=360$ & 14.688 \\
\hline Lighting & 96 & 76.8 & $(6 \times 30)=180$ & 13.824 \\
\hline \multirow[t]{2}{*}{$13 \mathrm{~A} \mathrm{SSO}$} & 1500 & 750 & $(4 \times 30)=120$ & 90.000 \\
\hline & & & Total kWh & 118.512 \\
\hline \multicolumn{2}{|c|}{$\begin{array}{r}\text { Tariff } \\
(k W h)\end{array}$} & $\begin{array}{c}\text { Rate } \\
\text { (cent/kWh) }\end{array}$ & $\begin{array}{l}\text { Power used } \\
(\mathrm{kWh})\end{array}$ & $\begin{array}{c}\text { Amount } \\
(\mathbf{R M})\end{array}$ \\
\hline \multirow{2}{*}{\multicolumn{2}{|c|}{$\begin{array}{l}\text { For the first } 200 \mathrm{kWh} \\
(1-200 \mathrm{kWh}) \text { per month }\end{array}$}} & RM0.218 & 118.5 & 25.83 \\
\hline & & Total & 118.5 & 25.83 \\
\hline
\end{tabular}


Table 3.5 - The total electricity bill of new bill after including the renewable energy fund

\begin{tabular}{cc}
\hline Usage of current per month & RM 25.83 \\
\hline $6 \%$ SST $(6 \% \times$ RM 25.83) & RM 1.55 \\
\hline KWTBB (1.60\% x RM 25.83) & RM 0.41 \\
\hline Total & RM 27.79
\end{tabular}

Table 3.6 - Comparison of electricity bill between old bill and new bill

\begin{tabular}{ccc}
\hline & Old bill & New bill \\
\hline Usage of current per month & RM 35.82 & RM 25.83 \\
\hline 6\% SST (6\% x RM 35.82) & RM 2.15 & RM 1.55 \\
\hline KWTBB (1.60\% x RM 35.82) & RM 0.57 & RM 0.41 \\
\hline Total & RM 38.54 & RM 27.79
\end{tabular}

It clearly shows that a considerable amount of money can be saved by using an energy-efficient load. After using an energy-efficient load, the monthly bill is around RM 27.79, which is around RM 10.75 less than the monthly bill before using an energy-efficient load. Also, from the calculation above, it can proceed to determine the maximum demand for the solar system simulation to see the system's behavior under AC load based on the maximum demand calculated.

\subsection{Solar and Battery Storage System Simulation}

The solar system simulation under 1000-Watt AC load is simulated using MATLAB/Simulink Software with the circuit shown in the engineering design part. This solar panel has an open-circuit voltage $\left(\mathrm{V}_{\mathrm{oc}}\right)$ of 37.75 volts, short circuit current $\left(\mathrm{I}_{\mathrm{sc}}\right)$ of 8.71 amps, maximum power voltage $\left(\mathrm{V}_{\mathrm{m}}\right)$ of 30.67 volts, maximum power current $\left(\mathrm{I}_{\mathrm{m}}\right)$ of 8.16amps, and this solar can produce $250 \mathrm{~W}$ of maximum power. By using 4 Series-connected modules, the solar panel can produce about 120 volts and approximately 1000 Watt. This solar system is concentrated on NEM which is a mechanism for B40 home to use solar energy that are produced for their own consumption means that the excess energy generated will be exported to TNB grid and will be turned to credit that may be used to offset part of the electricity bill [11]. Figure 3.7 shows the solar panel voltage, current, and power behavior under 1000-Watt AC load. When the solar irradiance impinging on the PV module surface is varied from about $1000 \mathrm{Wm}^{2}$ to $500 \mathrm{Wm}^{2}$, the solar voltage is slightly reduced to around 115 volts. However, the solar current and power are reduced half of the value when irradiance is $1000 \mathrm{Wm}^{2}$ to around 4 amps and $500 \mathrm{~W}$.

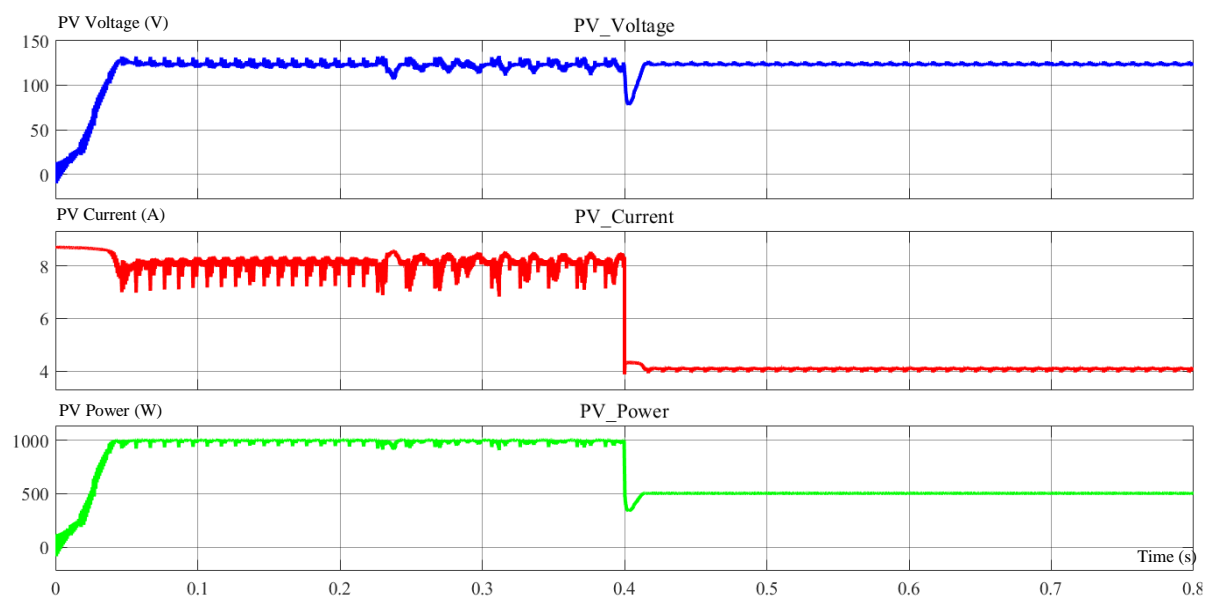

Figure 3.7 - Solar panel characteristic of voltage, current and power under 1000-Watt AC load

As for the boost converter, it is used to step up the solar output voltage from 120 volts to 240 volts. It was able to reach the desired voltage that this project need, which is 240 volts. This converter is controlled by using the incremental conductance (INC) algorithm. INC controller measures gradual changes in solar panel voltage and current to regulate voltage output of boost converter by adjusting the duty cycle based on the solar panel voltage and current. Figure 3.8 
shows the boost converter output voltages and current behavior under 1000-Watt AC load. As shown in Figure 3.8, the response of the output voltage is relatively slow and as the solar irradiance on the PV module surface drops from about $1000 \mathrm{Wm}^{2}$ to $500 \mathrm{Wm}^{2}$, the output voltage slightly drops to around 235 volts. If the solar efficiency falls below $50 \%$, the boost converter's output voltage will fall dramatically. However, it can be resolved by modifying the INC controller duty cycle as the controller will alter the PWM signal to make sure the boost converter output at around 240 volts, although the duty cycle cannot be greater than $90 \%$ because it will put the inductor under increased stress due to the increasing in inductor current, which can harm the circuit. An inductor with higher current rating can be used for a duty cycle greater than $90 \%$ as it can withstand the increasing of inductor current but a proper measurement need to be done to ensure it is not damaging the circuit and a simulation needed to find the maximum inductor current when the duty cycle more than $90 \%$ as it will be helpful to choose the right inductor.

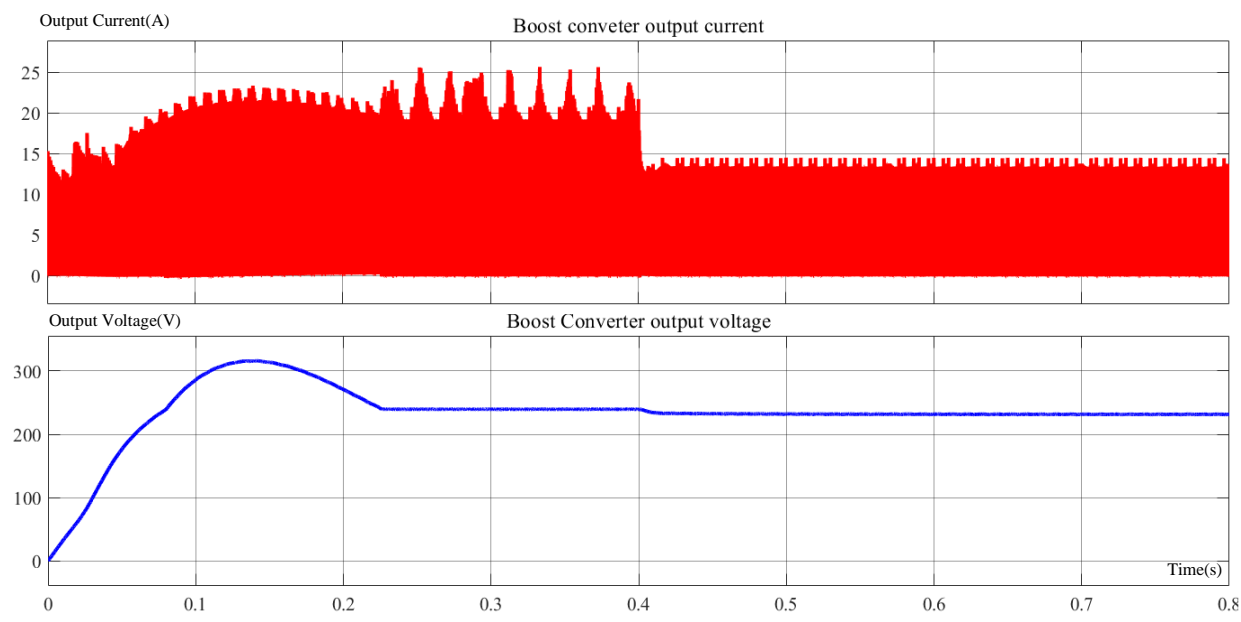

Figure 3.8 - Boost converter output voltages and current behavior under 1000-Watt AC load

However, the voltage is measured at the DC link resistor, which connects in between boost converter, bidirectional converter, and inverter. At the state when the solar irradiance on the PV module surface drops to 500 $\mathrm{Wm}^{2}$, the solar panel cannot keep the boost converter output voltage at DC link resistor to 240 volts. Bidirectional DCDC converters are used in this system where bidirectional power flow required in order to charge the battery and for the battery to keep the voltage at the DC link resistor to around 240 volts when its voltage drop below that. The bidirectional converter will start to operate in boost mode to boost the input voltage from the battery to keep the voltage at the DC link resistor to 240 volts. At the same time, the battery will start to discharge as the voltage at the DC link resistor drop. On the other side, when the solar irradiance on the PV module surface is about $1000 \mathrm{Wm}^{2}$, the DC link resistor voltage is at 240 volts, making the controller detect the voltage changes and initiate a bidirectional converter to operate in buck mode to charge the battery. Figure 3.9 shows the battery state of charge, voltage, and current. Nevertheless, the battery is charging at a slow pace and discharges faster, which makes them inefficient. In order to make the battery charge faster, the output current of bidirectional converter in buck mode need to be tuned until it close to the nominal discharge current of the battery. Still, it should not exceed the battery's nominal discharge current because it is not recommended to charge or discharge batteries at their full current ratings as it will affect the battery life span. To overcome the battery discharge faster, a supercapacitor can be used as an additional backup for the battery to reduce the discharge time of the battery and will respectively reduce the battery load consumption as the supercapacitor are act like a battery, but rather than storing energy in the form of chemicals, supercapacitors store electricity in a static state, making them better at rapidly charging and discharging energy. 


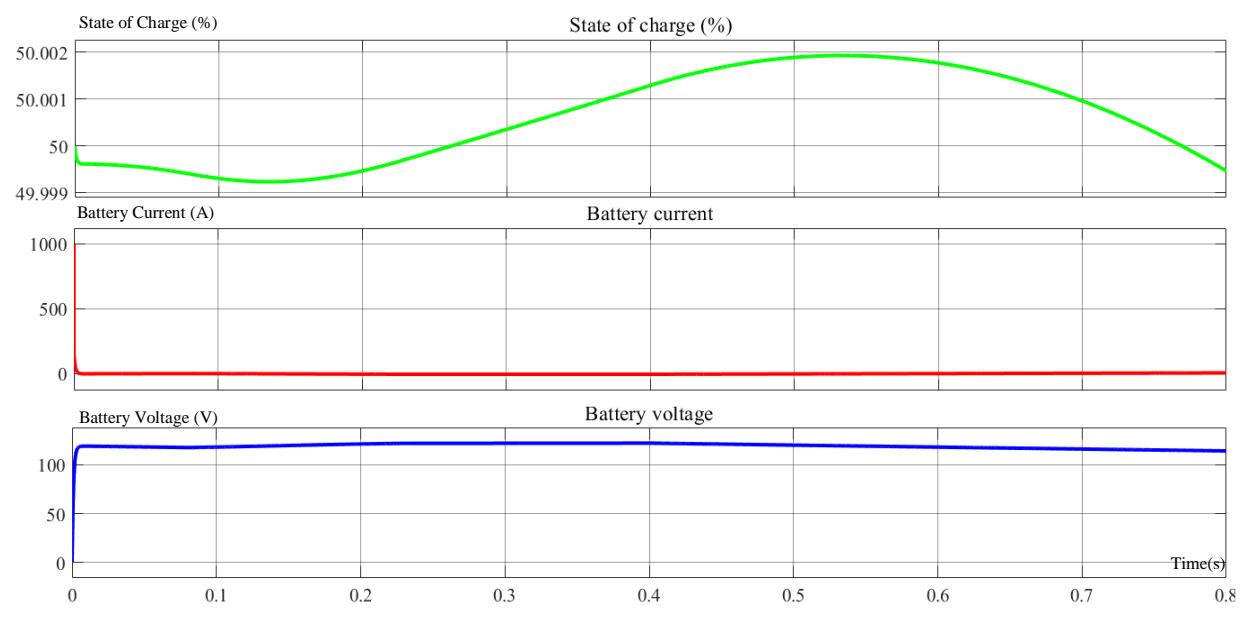

Figure 3.9 - Battery state of charge, voltage and current

This solar system also uses an inverter to convert DC input voltage and current to AC output voltage and current. The inverter used is a single-phase full-bridge inverter which consists of 4 choppers where each chopper consists of a pair of a transistor or a thyristor and a diode. This inverter generates a square wave AC output voltage by adjusting the switch turning ON and OFF based on the switching frequency set in the PWM signal generator. As the solar irradiance impinging on the PV module surface varies from about $1000 \mathrm{Wm}^{2}$ to $500 \mathrm{Wm}^{2}$, the inverter's voltage output can remain at around 240 volts with the help of the battery. Figure 3.10 shows the inverter voltage and current behavior under 1000-Watt AC load. The single-phase full-bridge inverter produce a magnitude of load voltage equal to the magnitude of the output voltage of boost converter which is 240 volts. The sequential triggering of MOSFETs arranged diagonally opposite in a single-phase full bridge inverter. MOSFET M3 \& M4 will be triggered for half of the time period, whereas M1 \& M2 will be triggered for the remaining half of the time period. Only two MOSFETs are turned on in half of the time which make the magnitude of the load voltage in reverse polarity. This is why the output voltage in the voltage waveform is negative. Because of the filtering property of the inductance and capacitance, the current will have more sinusoidal quality than the voltage for the AC load.



Figure 3.10 - Inverter voltage and current behavior under 1000-Watt AC load

\section{Conclusion}

In conclusion, the aims for this project are achieves which are to design and simulate the solar energy system including battery storage in suitable software for residential house especially in B40 community home and also to analyze the potential of battery storage in order to store the energy from solar panel. This project is achieved by designing the system by using the MATLAB software in order to produce the result of energy efficiency by using the renewable energy which is solar system and also battery storage. The energy consumption of B40 community home is calculated and the electricity bill between the old and new bills after using energy-efficient load such as ceiling fan, lighting and socket in B40 house is compared in order to analyze which one is better and have the lowest monthly bill. After using an energy-efficient load, the monthly new bill is around RM 27.79, which is around RM 10.75 less than the monthly old bill before using an energy-efficient load and can be concluded that the use of renewable energy in B40 
community home can saving the energy and also money. Then, the data obtained from the new bill calculation under maximum demand is used for the solar system simulation using MATLAB software in order to analyze the system's behavior under AC load. With the help of this system, it shown that this system can decrease the hardship of B40 community in financial because it will decrease their electric bill or drastically reduce it to the point that electricity costs are no longer a major factor in their budget.

\section{Acknowledgement}

The Author would like to thank the Faculty of Electrical and Electronic Engineering, Universiti Tun Hussein Onn Malaysia for the facilities that has been provided and for its support.

\section{References}

[1] Faisal Bin Shahin, Pranti Tawheed, Md. Faijul Haque, Md. Rakib Hasan, Md. Nasfikur R. Khan. (September 2017). Smart Home Solution with Sun Tracking Solar Panel. International Conference on Advances in Electrical Engineering. DOI:10.1109/ICAEE.2017.8255457

[2] Jen-Li Lim. (July 27, 2020). Is the Income Gap Between the B40, M40 And T20 Groups Widening? Imoney Malaysia. Retrieved from https://www.imoney.my/articles/b40-m40-t20-income-gap

[3] Isabelle. (May 6, 2021). What is the B40, M40, and T20 income Classification in Malaysia? Propsocial. Retrieved from https://www.propsocial.my/topic/2404/what-is-the-b40-m40-and-t20-income-classification-inmalaysia-posted-by-propsocial-editor

[4] Syed Shah Alam, Nor Asiah Omar, Mhd. Suhaimi Bin Ahmad, H.R Siddiquei, Sallehuddin Mohd. Nor. (December 2013). Renewable Energy in Malaysia: Strategies and Development. Environmental Management and Sustainable Development. DOI:10.5296/emsd. v2i1.3197

[5] Siti Norasyiqin Abdul Latif, Meng Soon Chiong, Srithar Rajoo, Asako Takada, Yoon-Young Chun, Kiyotaka Tahara, Yasuyuki Ikegami. (April 15, 2021). The Trend and Status of Energy Resources and Greenhouse Gas Emissions in the Malaysia Power Generation Mix. Energies

[6] P.D. Abd. Aziz, S.S.A. Wahid, Yanuar Z. Arief, N. Ab. Aziz. (September 15, 2016). Evaluation of Solar Energy Potential in Malaysia. Science Alert

[7] Tarlochan Kaur, Jaimala Gambhir, Sanjay Kumar. (2016). Arduino Based Solar Powered Battery Charging System for Rural SHS. IEEE Explore

[8] Ain Umaira MdShah, Syafiqah Nur Azrie Safri, Rathedevi Thevadas, Nor Kamariah Noordin, Azmawani Abd Rahman, Zamberi Sekawi, Aini Ideris, Mohamed Thariq Hameed Sultan. (August 2020). COVID-19 outbreak in Malaysia: Actions taken by the Malaysian government. International Journal of Infectious Diseases. ScienceDirect

[9] Ikhwab Rivai. (October 18, 2020). Can the poor in Malaysia cope with the challenges posed by the COVID-19 pandemic? CNA Insider

[10] M. Hedlund. (2010). Design and construction of a bidirectional DCDC converter for an EV application. Uppsala Universitat, Uppsala

[11] Tenaga Nasional Berhad. (2018). What is NEM? Retrieved form https://www.tnb.com.my/solar/faq 